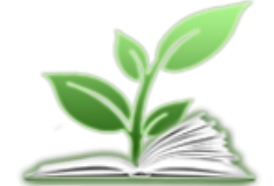

\SSW १९९१+्8208

Revista Verde de Agroecologia e Desenvolvimento Sustentável

http://www.gvaa.com.br/revista/index.php/RVADS

REVISÃO BIBLIOGRÁFICA

DOI: http://dx.doi.org/10.18378/rvads.v10i5.2793

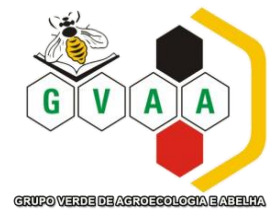

\title{
Licenciamento ambiental: Conflito de interesses
}

\section{Environmental permit: conflict of interests}

\author{
Maria da Silveira Câmara Neta ${ }^{1}$, Karidja Carlos de F. Moura ${ }^{2}$, Nildo da Silva Dias ${ }^{3}$, Ana C. Medeiros Souza ${ }^{4}$, Kallyo H. \\ Santos Moura ${ }^{5}$
}

Resumo: O licenciamento ambiental foi criado pela Legislação Federal como um dos instrumentos da Política Nacional do Meio Ambiente na Lei $\mathrm{N}^{\circ}$ 6.938/81, tornando-se obrigatório para todas as atividades que possam interferir na qualidade do meio ambiente. Este instrumento visa a preservação, melhoria e recuperação da qualidade ambiental e proporcionar a vida, assegurando condições ao desenvolvimento socioeconômico, aos interesses da segurança nacional e a proteção da dignidade da vida humana. Nesse contexto, objetivou-se analisar o processo de licenciamento ambiental enquanto instrumento de política ambiental, evidenciando as principais dificuldades para a obtenção da licença ambiental. Entretanto, é imprescindível o conhecimento dos empreendedores a respeito dos danos ambientais caudados pelas suas atividades para que possam se adequar às exigências da prevenção aos recursos naturais e da compensação ambiental que lhes compete. Há necessidade de adequação do processo de licenciamento ambiental que atenda satisfatoriamente órgãos ambientais e empreendedores, primando pela agilidade, qualidade e eficiência e com vistas a tornar-se um instrumento eficaz no que concerne à proteção ambiental sem inviabilizar o desenvolvimento econômico/social necessário e de forma sustentável.

Palavras-chave: Legislação ambiental; Análise de processos; Órgãos ambientais.

Abstract: The environmental permit was created by federal law as an instrument of the National Environmental Policy Act in 6938/81, making it mandatory for all activities that can affect the quality of the environment. This instrument aims at the preservation, improvement and restoration of environmental quality and provide life by ensuring conditions for sustainable socio-economic interests of national security and protecting the dignity of human life. In this context, this paper aims to analyze the environmental licensing process as an instrument of environmental policy, highlighting the main difficulties for obtaining the environmental permit. However, it is essential to know the entrepreneurs about the environmental damage caused by their activities so that they suit the requirements of prevention of natural resources and environmental compensation that they are responsible. There is need for adequacy of the environmental licensing process that meets satisfactorily environmental agencies and entrepreneurs, excelling in agility, quality and efficiency and in order to become an effective instrument with regard to environmental protection without derail the economic/social development needed and sustainably.

Keywords: Environmental legislation; Process analysis; Environmental agencies.

\footnotetext{
*Autor para correspondência

Recebido para publicação em 25/07/2014; aprovado em 22/04/2015

${ }^{1}$ Especialista em Gestão Ambiental, Faculdade do Vale do Jaguaribe (FVJ); mariasilveira@rn.gov.br

${ }^{2}$ Professora/Pesquisadora PNPD/CAPES da Universidade Federal Rural do Semiárido (UFERSA); karidja@ufersa.edu.br

${ }^{3}$ Professor Adjunto IV do Departamento de Ciências Ambientais e Tecnológicas, UFERSA; nildo@ufersa.edu.br

${ }^{4}$ Mestre em Manejo de Solo e Água, UFERSA; anaclaudia.gambiental@ hotmail.com

${ }^{5}$ Eng. Agrônomo/Consultor do SEBRAE/RN; kallyojr@gmail.com
} 


\section{INTRODUÇÃO}

O licenciamento ambiental surge como um instrumento de grande importância, envolvendo as indústrias brasileiras que passam a reconhecer sua responsabilidade no processo de degradação dos recursos naturais. Do ponto de vista da CNI, a necessidade de aprimorar a legislação, como apoio à competitividade industrial e ao crescimento da economia, ocorre em um momento especial: a responsabilidade socioambiental é cada vez mais valorizada pelas empresas brasileiras.

$\mathrm{Na}$ busca pela eficiência e pelo aumento da qualidade dos produtos e serviços, a indústria adota sistemas de gestão ambiental e processos de produção mais limpos. Para que ocorram de modo eficaz, eles dependem de uma legislação compatível com as atuais necessidades do setor. Nesse contexto, é fundamental que o processo de licenciamento ambiental ganhe em rapidez, transparência e objetividade, de forma a promover o crescimento econômico em conjunto com a conservação do meio ambiente. Ainda de acordo com a CNI, o mapa estratégico da indústria (2007-2015) define como objetivo do setor produtivo o desenvolvimento sustentável. Trata-se de um desafio complexo para uma sociedade marcada pela desigualdade e pela necessidade de crescer e promover uma maior inclusão social.

No tocante a legislação ambiental brasileira, reconhecida por muitos autores como uma das melhores do mundo, é importante salientar que as Leis e Resoluções que regem as questões ambientais estabelecem, no âmbito da sua competência, normas e padrões compatíveis com o meio ambiente ecologicamente equilibrado e essencial qualidade de vida. Essa responsabilidade abrange o Poder Público e a coletividade na defesa dos recursos naturais utilizados e, as empresas brasileiras como maiores consumidores dessas riquezas, têm o dever de preservá-las, assim garantidas pelo Art. 225 da Constituição Federal.

As atividades ou empreendimentos que precisam ser licenciados são classificados quanto ao seu porte e potencial poluidor/degradador, levando em consideração suas especificidades e os possíveis riscos ambientais. Com base nesses parâmetros o órgão ambiental competente define quais os documentos e estudos necessários para conceder a licença ambiental. Desta forma, cada empreendimento terá o grau de exigibilidade inerente às suas funções, resultando em uma análise técnica sempre criteriosa.

A Política Nacional do Meio Ambiente - PNMA, instituída pela Lei $\mathrm{n}^{\circ} 6.938 / 81$ criou o licenciamento ambiental como um dos seus instrumentos com aplicação obrigatória para uma gama de atividades consideradas efetivamente poluidoras, constantes da Resolução CONAMA $n^{\circ}$ 237/1997. Como principal objetivo dessa Lei estão a preservação, melhoria e recuperação da qualidade ambiental, visando assegurar no país condições ao desenvolvimento sócio-econômico, aos interesses da segurança nacional e a proteção da dignidade da vida humana. O CONAMA é um órgão consultivo e deliberativo do SISNAMA - Sistema Nacional do Meio Ambiente, que é composto pelos órgãos e entidades da União, dos Estados, do Distrito Federal, dos Territórios e dos Municípios.

De acordo com Sirvinskas (2003), o SISNAMA tem por finalidade dar cumprimento ao princípio matriz previsto na Constituição Federal e nas normas infraconstitucionais nas diversas esferas da Federação. Ainda segundo esse autor, essa finalidade poderá estabelecer uma rede de agências governamentais, assegurando mecanismos capazes de implementar eficientemente a Política Nacional do Meio Ambiente.

O licenciamento ambiental trata-se de um procedimento administrativo pelo qual o órgão ambiental competente autoriza a localização, instalação, ampliação e a operação de empreendimentos que fazem uso dos recursos ambientais. De acordo com Godoy (2005) "é um meio de controle preventivo de atividades potencialmente poluidoras que condicionou a exploração ou uso de um bem ambiental ao cumprimento de requisitos de proteção do meio ambiente".

Nesse contexto, citamos os tipos de licença, com seus prazos de validade de acordo com a Resolução CONAMA n 237/1997, art. $8^{\circ}$ I, II, III, art 18.

A Licença Prévia (LP) é concedida na fase preliminar do planejamento do empreendimento ou atividade onde são aprovadas sua localização e concepção, atestando a viabilidade ambiental e estabelecendo os requisitos básicos e condicionantes a serem atendidos nas próximas fases de sua implementação. O prazo de validade devera ser no mínimo, o estabelecido pelo cronograma, não podendo ser superior a cinco anos, no máximo. É importante destacar que esta licença, mesmo sendo a que inicia o processo, não autoriza o início das obras, contudo, "por ser a primeira licença ambiental concedida deve funcionar como um alicerce, verdadeira base de sustentação ambiental, para implantação do projeto" (FARIAS 2007).

Licença de Instalação (LI) autoriza a instalação do empreendimento ou atividade de acordo com as especificações constantes nos planos, programas e projetos aprovados, incluindo as medidas de controle ambientais e demais condicionantes, da qual constituem motivo determinante. Nessa fase é elaborado o projeto executivo da atividade, o qual constitui em uma reestruturação do projeto original, porém com mais detalhes. Segundo Bezerra (2008 p. 96) essa mudança define medidas técnicas responsáveis por "aliar a instalação do empreendimento com a preservação do ecossistema atingido". O prazo de validade deverá ser no mínimo, o estabelecido no cronograma, não podendo ser superior a seis anos.

Licença de Operação (LO) autoriza a operação da atividade ou empreendimento, após a verificação do efetivo cumprimento do que consta das licenças anteriores, com as medidas de controle ambiental e condicionantes determinados para a operação. "Esta licença conclui o procedimento licenciatório, autorizando o início das atividades desde que preenchidos (sic) para tanto (BEZERRA, 2008). O prazo de validade deverá considerar os planos de controle ambiental e será, no mínimo, de quatro anos, e no máximo, de dez anos. Salientamos, porém, que o processo de licenciamento não tem um fim, haverá sempre uma renovação da licença de operação.

A Lei ainda concede dois tipos de licenças que são aplicadas em situações especiais como um empreendimento considerado de menor porte e menor potencial poluidor. Nesse caso, o órgão ambiental poderá conceder um procedimento simplificado, independendo da fase em que a atividade se encontre. Em outra situação, por sinal bastante comum, ocorre quando o empreendimento já se encontra em plena atividade, mas operando sem a devida licença 
ambiental. Neste caso, será adotado o licenciamento ambiental corretivo, uma vez que este engloba as três fases regulares já citadas.

Os Estados poderão aumentar as modalidades de licenciamento, adicionar exigências para cada fase, não podendo, contudo, exigir menos (MACHADO, 2006).

Segundo Farias (2007), cada etapa do licenciamento deve terminar com a concessão da licença ambiental correspondente, de maneira que as licenças ambientais servem para formalizar que até aquela etapa o proponente da atividade está cumprindo o que a legislação ambiental e o que a administração pública determinam no âmbito do procedimento de licenciamento ambiental por parte da autoridade competente.

Apesar de estar bem estruturado do ponto de vista legal, o processo de licenciamento ambiental, na prática, tem ocasionado discussões na academia e na sociedade de um modo geral acerca de sua morosidade e lentidão. De modo geral, os processos demoram a ser concluído, gerando transtornos ao empreendedor e à sociedade. Entre as possíveis causas desse problema, citam-se com frequência a falta de estrutura dos órgãos ambientais, seja quanto à carência de recursos humanos ou de equipamentos e materiais necessários ao processo.

Nesse contexto, objetivou-se analisar o processo de licenciamento ambiental enquanto instrumento de política ambiental, evidenciando as principais dificuldades para a obtenção da licença ambiental.

\section{MATERIAL E MÉTODOS}

Os procedimentos metodológicos que nortearam o desenvolvimento deste trabalho são de cunho analítico, explicativo e qualitativo. Trata-se de um trabalho apoiado em pesquisa bibliográfica realizada a partir do registro disponível, decorrente de pesquisas anteriores, em documentos impressos, como livros, artigos, teses e etc.

A referência principal utilizada para este trabalho foi o estudo realizado pela Confederação Nacional das Indústrias CNI, intitulado "Empresas enfrentam dificuldades no licenciamento ambiental" (CNI, 2007), sendo priorizado os relatos da experiência da pesquisa da CNI que descrevem as maiores dificuldades encontradas para adquirir a licença ambiental. A partir dele, fez-se uma análise sobre a importância do licenciamento ambiental enquanto instrumento de política ambiental, mas também das ferramentas que auxiliam esse processo.

Como informações secundárias, foram utilizadas fontes de pesquisa como as Leis e Resoluções que regulamentam o tema, bem como, documentos disponíveis em sites conceituados.

\section{RESULTADOS E DISCUSSÃO}

\section{Licenciamento ambiental nas atividades econômicas e} sociais

A evolução histórica dos problemas ambientais obrigou, de certo modo, a legislação brasileira a se preparar para conter a deterioração da qualidade ambiental e para possibilitar a sustentabilidade nos processos de exploração e apropriação dos recursos naturais. Nesse contexto, o licenciamento surge como um instrumento de grande importância e envolve as indústrias brasileiras, que passam a reconhecer sua responsabilidade no processo de degradação dos recursos dos quais se apropria e transforma.

Entretanto, o mais importante é o destaque para o caráter de divisor de águas que deve ser reservado à Lei 6.938/81, responsável pela cristalização da consciência ecológica na sociedade civil brasileira (GODOY, 2005). O autor destaca a importante contribuição da lei quando afirma que sem ela, a sistematização dos procedimentos, a busca pela excelência empresarial sob o ponto de vista de "limpar" as empresas e seus sistemas de produção, bem como a crescente cobrança da sociedade para os cuidados com o meio ambiente estaria ainda em seus passos iniciais.

Diante disso, as indústrias brasileiras começam a sentir a necessidade de implementarem práticas de gestão ambiental e já ampliam os investimentos destinados a tal fim, em resposta a uma sociedade que se torna cada vez mais exigente. Essa preocupação está refletida na adoção de medidas gerenciais relacionadas ao compromisso político social das empresas, que muitas vezes não se concretiza, ou pelo menos demora a se concretizar, diante das inúmeras dificuldades enfrentadas para receberem o licenciamento ambiental.

$\mathrm{Na}$ última sondagem sobre o tema realizada pela CNI (2007), ficaram evidenciados alguns entraves para obtenção de licenciamento ambiental que ocasionaram uma grande parada nos investimentos do setor privado. Entre os problemas detectados, merece destaque a demora na análise dos processos, o custo elevado para cumprir as obrigações exigidas e a dificuldade de identificar os critérios técnicos exigidos pelos órgãos ambientais.

A preocupação demonstrada pelos empresários com a demora na análise dos processos, um dos itens mais citados na sondagem, justifica-se por provocar um efeito dominó de perdas de vez que os contratos com os fornecedores acabam não sendo cumpridos. A morosidade dos processos de licenciamento ambiental aparece como principal problema enfrentado, apesar dos órgãos ambientais terem prazo para análise dos processos de licenciamento ambiental, esse tempo é geralmente ultrapassado, não acompanhando a demanda de processos e pela falta de estrutura (técnicas e humanas) dos próprios órgãos ambientais.

No entanto, um fator agravante ocasionado por parte das empresas é que muitas vezes a documentação apresentada não está coerente com o tipo de empreendimento, precisando ser refeita ocasionando um prolongamento da finalização do processo.

Como segundo obstáculo destaca-se os custos investidos para cumprir as exigências ambientais, decorrentes da contratação de consultoria para aquisição de plantas, projetos, estudos ambientais, aquisição de equipamentos, o valor das licenças, entre outros.

Em seguida, a dificuldade de identificar e atender os critérios técnicos exigidos, ampliado pela falta de esclarecimento por parte dos órgãos ambientais que, por sua vez, mantêm um distanciamento significativo com os empreendedores, impedindo que o licenciamento ambiental seja uma prática eficaz de proteção e indução do desenvolvimento sustentável.

De acordo com as dificuldades elencadas pela sondagem da CNI é possível considerar que esses fatores ocorrem, muitas vezes, pela falta de conhecimento e compromisso do empreendedor com os recursos naturais dos quais ele precisa dispor para sua atividade. Atitudes como 
estas resultam em estudos, plantas e projetos mal elaborados e ineficientes na comprovação real dos danos causados ao meio ambiente. É preciso ser criterioso na contratação de bons profissionais para elaboração desses documentos e existir um conhecimento mínimo dos empresários a cerca do está sendo feito. Em muitos casos o que poderia ocasionar redução de tempo e custo, transforma-se em atrasos e gastos ainda maiores. Com base na Resolução do CONAMA no 237/97 em seu Art. $9^{\circ}$, o órgão ambiental competente pode solicitar esclarecimentos e complementações, em decorrência da análise dos documentos, dos projetos e estudos apresentados quando estes não são satisfatórios. É possível também que em alguns casos seja pertinente realizações de audiências públicas e, quando couber, parecer jurídico.

Segundo Antunes (2004), o licenciamento ambiental deve ser considerado um ativo intangível, pois ele é uma condição essencial e sine qua non para o regular funcionamento de uma empresa. A inexistência do licenciamento é uma ameaça constante ao desenvolvimento de atividades industriais e econômicas, visto que a pressão pela conformidade ambiental de uma firma não se limita aos órgãos públicos encarregados de controle ambiental. Atualmente, a conformidade ambiental das empresas é tema que extrapola a administração pública do meio ambiente e se alastra pela sociedade, que, mediante a constante vigilância das organizações não-governamentais (ONGs), exige dos empreendedores uma total submissão à legislação ambiental.

$\mathrm{O}$ autor supracitado ainda esclarece que "os próprios organismos financeiros, cada vez mais, exigem padrões ambientais adequados para concessão de empréstimos. O licenciamento ambiental, nesse caso, é a exigência mínima que estabelecem como pré-requisito para liberação de empréstimos.

Desta forma, percebe-se que as questões ambientais estão interligadas ao poder econômico e social do país. Como os problemas ambientais são em regra causados pelas atividades econômicas, a obtenção de um meio ambiente saudável deve ser um resultado da atuação responsável dos diversos setores da atividade econômica. É nesse contexto que desponta a importância da responsabilidade empresarial no trato com o meio ambiente, de maneira a fazer com que o crescimento econômico não se torne um obstáculo à defesa do meio ambiente (FARIAS, 2006).

Evidencia-se desse modo, a exigência do mercado por empresas comprometidas com a preservação dos recursos naturais e que estejam preocupadas em adotar planos e medidas mitigadores em suas ações.

Sobre esse fato, Farias (2006) comenta como a problemática ambiental é causada por um modelo de desenvolvimento econômico que ignora o meio ambiente, o Licenciamento ambiental parece dispor de uma eficácia diferenciada e precisa tendo em vista o desenvolvimento econômico, ao colocar limites à implantação, à operação e à expansão das atividades econômicas.

Mesmo considerando que a legislação que normatiza todo o processo de licenciamento é bastante exigente, porém necessária para evitar os abusos e a total falta de controle diante dos impactos ambientais gerados pelos empreendimentos. Talvez por esta exigência, a falta de estrutura dos órgãos ambientais torne o processo mais criterioso e consequentemente mais lento.

\section{A importância dos estudos ambientais}

Para a implantação de alguns empreendimentos é necessário a aquisição de estudos ambientais que detectem sua viabilidade ou não. Portanto, a Constituição Federal, em seu Art. 225, inciso IV, estabelece diversos princípios em defesa da qualidade ambiental, inclusive a necessidade de que o poder público exija "para instalação de obra ou atividade potencialmente causadora de significativa degradação do meio ambiente, estudo prévio e impacto ambiental, a que se dará publicidade".

Diversos tipos de estudos ambientais foram criados, por diferentes instrumentos legais federais, estaduais ou municipais, com o intuito de fornecer as informações e análises técnicas para subsidiar o processo de licenciamento (SANCHEZ, 2006).

A Avaliação de Impactos Ambientais (AIA) é um dos instrumentos da PNMA e, além de uma efetiva contribuição, associada ao licenciamento ambiental poderá exigir a estruturação dos órgãos ambientais em todos os Estados da União. Diante disso, poderá impor aos empreendedores privados e públicos novos requisitos para planificação dos projetos, aliados as medidas mitigadoras e compensatórias (SANCHEZ, 2006).

Segundo Cunha e Guerra (2005) a AIA pode ser definida como um instrumento de política ambiental formado por um conjunto de procedimentos capaz de assegurar, desde o início do processo, que se faça um exame sistemático dos impactos ambientais de uma ação proposta (projeto, programa, plano ou política) e de suas alternativas, que os resultados sejam apresentados de forma adequada ao público e aos responsáveis pela tomada de decisão, e por eles devidamente considerados.

Denomina-se de impacto ambiental qualquer alteração das propriedades físicas, químicas e biológicas do meio ambiente. Essas modificações podem vir por qualquer forma de matéria ou energia resultante das atividades humanas, que afetam direta ou indiretamente, a saúde, a segurança e o bemestar da população. Os impactos ambientais ainda podem afetar as atividades sociais e econômicas, a biota, as condições estéticas e sanitárias do meio ambiente e a qualidade dos recursos ambientais de acordo com o CONAMA nº 001/1986 (BRASIL, 1986).

A norma NBR ISO 14001:2004 define impacto ambiental "como qualquer modificação do meio ambiente, adversa ou benéfica, que resulte, no todo ou em parte, das atividades, produtos ou serviços de uma organização".

De acordo com Rocha et al. (2004) os impactos ambientais podem ser classificados quanto aos aspectos: positivos e negativos; diretos e indiretos; imediatos ou em longo prazo; temporários e permanentes; grau de reversibilidade; de propriedades cumulativas e sinérgicas; das distribuições dos ônus e benefícios sociais.

O EIA/RIMA, denominado de Estudo de Impacto Ambiental acompanhado do Relatório de Impacto Ambiental, são aplicados aos empreendimentos e atividades impactantes. O EIA trata-se de um estudo detalhado sobre os impactos inerentes a determinada atividade, que utiliza termos essencialmente técnicos, enquanto o RIMA, é um resumo desse estudo elaborado com uma linguagem clara e objetiva para ser compreendido por pessoas leigas. O PCA/RCA, denominados de Plano de Controle Ambiental e seu respectivo Relatório de Controle Ambiental, são exigidos em empreendimentos que não gerem grandes impactos. E o 
PRAD é o Plano de Recuperação de Áreas Degradadas (BRASIL, 1997).

A Resolução CONAMA no 371/2006 estabelece a Compensação Ambiental, onde os órgãos ambientais podem calcular, cobrar, aplicar, aprovar e controlar os gastos advindos destes recursos. O valor cobrado nessa ação é de $0,5 \%$, sendo este fixado pelo órgão ambiental competente, sempre considerando o grau de impacto ambiental causado pelo empreendimento.

A compensação ambiental decorre da implantação de empreendimentos de significativos impacto ambiental com fundamentos no EIA/RIMA, e é destinada para implantação ou manutenção de uma unidade de conservação. Este fato acaba por motivar uma disputa entre os órgãos ambientais, uma vez que se trata sempre de empreendimentos de grande porte, ocasionando recursos consideráveis para a região. No entanto, este fato também gera discordância com o empreendedor no tocante a valores da ação compensatória, uma vez que, agregam-se outras despesas como as taxas do próprio licenciamento e do EIA/RIMA.

\section{CONCLUSÕES}

O licenciamento ambiental constitui-se em um dos mais importantes instrumentos da Política Nacional do Meio Ambiente e é também ferramenta do poder público para preservar e controlar o uso dos recursos naturais. Dessa forma, procura fazer com que as atividades econômicas, potencial ou efetivamente poluidoras, cumpram sua função social especialmente no que diz respeito ao meio ambiente e qualidade de vida da coletividade.

De acordo com a pesquisa, os empreendedores alegam que são grandes as dificuldades para concluir o processo de licenciamento ambiental, ocasionando o atraso da emissão da licença e, consequentemente no funcionamento da atividade. Entretanto, é importante ressaltar que os empreendedores conheçam os possíveis danos ambientais inerentes à sua atividade, para ter consciência da necessidade do controle exigido pelo licenciamento ambiental.

No Brasil, tudo que se refere às questões ambientais, seja para prevenção ou mitigação dos impactos, são ações consideradas relativamente novas e que ainda não se tornaram prioridades para os governos. Neste sentido, pode-se perceber a necessidade de estruturação dos órgãos ambientais que compõem o Sistema Nacional de Meio Ambiente SISNAMA, buscando melhorias quanto às suas competências quais sejam:, a simplificação do processo de licenciamento ambiental quando possível e a implementação de uma política de informação e informatização dos órgãos ambientais, com vistas à maior transparência, automação e sistematização do processo de licenciamento e padronização das decisões.

Há necessidade de adequação do processo de licenciamento ambiental que atenda satisfatoriamente órgãos ambientais e empreendedores, primando pela agilidade, qualidade e eficiência e com vistas a tornar-se um instrumento eficaz no que concerne à proteção ambiental sem inviabilizar o desenvolvimento econômico/social necessário e de forma sustentável.

\section{REFERÊNCIAS}

ANTUNES, P. de B. A questão dos ativos ambientais. Gazeta Mercantil. Disponível em: <http://www. dannemann.com.br/site.cfm?app=show $\& d s p=$ pba14\&pos $=5.1$ 5\&lng=pt> Acesso em: 3 de ago. 2011.

ASSOCIAÇÃO BRASILEIRA DE NORMAS TÉCNICAS. NBR 14001: Sistema da gestão ambiental especificação e diretrizes para uso. Rio de Janeiro, 1996.

BEZERRA, F. C. P. O licenciamento ambiental como instrumento de um desenvolvimento verdadeiramente sustentável. 172 f. Dissertação (Pós-graduação) - Curso de Direito, Universidade Federal do Rio Grande do Norte, Natal, 2008.

BRASIL. Congresso Nacional. Lei 6.938 de 31 de agosto de 1981. Dispõe sobre a Política Nacional do Meio Ambiente, seus fins e mecanismos de formulação e aplicação, e dá outras providências. Disponível em: <http://www.planalto.gov.br/ccivil_03/Leis/L6938org.htm>. Acesso em: 23 de jul 2011.

Confederação Nacional da Indústria - CNI. A indústria e o meio ambiente. Disponível em: <http://www.ambiente.ambientebrasil.com.br/gestão/artigos.h tml>. Acesso em: 12 mai. 2009.

Confederação Nacional da Indústria - CNI. Dificuldade de licenciamento ambiental inibe investimentos. 2007. Disponível em: <http://www.ambiente.ambientebrasil.com.br/gestão/artigos.h tml $>$. Acesso em: 25 jul. 2011.

CUNHA, S. B.; GUERRA, A. J. T.(orgs.). Avaliação e perícia ambiental. 6. ed. Rio de Janeiro: Bertrand Brasil, 2005.

FARIAS, T. Licenciamento ambiental e responsabilidade empresarial. Disponível em: <http://www.ambitojuridico.com.br/site/index.php?n_link=re vista_artigos_leitura\&artigo_id=1171>. Acesso em: 3 de ago. 2011.

FARIAS, T. Licenciamento ambiental: aspectos teóricos e práticos. Belo Horizonte: Fórum, 2007.

GODOY, A. V. de. A eficácia do licenciamento ambiental como um instrumento público de gestão do meio ambiente. Brasília: OAB Editora, 2005.

MACHADO, Paulo Affonso Leme. Direito ambiental brasileiro. 11. ed. São Paulo: Malheiros Editores, 2003.

SANCHEZ, L. E. Avaliação de Impactos Ambientais: conceitos e métodos. São Paulo: Oficina de Textos, 2006.

SIRVINSKAS, L. P. Manual do direito ambiental. 2 ed. São Paulo: Saraiva, 2009. 